\title{
Comparison between different modalities of Endovascular treatment in Carotid Cavernous Fistula (CCF) and its short term outcome - Our Experience
}

\author{
Sultana $\mathrm{S}^{1}$, Islam $\mathrm{S}^{2}$, Rana $\mathrm{S}^{3}$, Rifat $\mathrm{KJ}^{4}$, Azad $\mathrm{AK}^{5}$, Hasan $\mathbf{M}^{6}$, Ansari $\mathrm{A}^{7}$, \\ Sarkar $\mathrm{AC}^{8}$, Ilias $\mathrm{ANM}^{9}$, Alam $\mathrm{MR}^{10}$.
}

\begin{abstract}
Introduction: Endovascular treatment offers different technique (Balloon assisted coiling / simple coiling, glue embolization) to treat Carotid Cavernous Fistula (CCF). This less invasive approach avoids morbidity and residual fistulas. The choice of treatment depends on the anatomy of the fistulas and cost effectiveness.

Objective: To describe different endovascular treatment option of Carotid Cavernous fistulas (CCF), its short term outcome (clinical and angiographical) and to compare between trans-venous coiling and trans-arterial balloon assisted sinus coiling.

Method: We have treated nine (9) cases of CCF during a period of three years. Out of them eight patients had direct $C C F$ and one had indirect CCF. In two patients simple coiling done through trans-venous route and in another three patients through trans-arterial route. Balloon assisted coiling through trans-arterial route done in three patients. In two patients trans-arterial glue embolization was done.

Results: Successful obliteration of fistula was achieved in all cases. Vision was improved in eight (8) patients. Postoperatively some proptosis remains in two patients. In one patient there was reappearance of proptosis two months after treatment, then balloon assisted coiling was done. One patient died from complication of glue (NBCA).

Conclusion: Endovascular treatment is the mainstay of treatment in CCF. Trans-venous is the treatment of choice but recently balloon assisted sinus coiling through trans-arterial route is adopted.
\end{abstract}

Key words: Carotid, cavernous, fistula, endovascular treatment, balloon assisted sinus coiling.

Bang. J Neurosurgery 2019; 8(2): 68-76

\section{Introduction:}

Carotid-cavernous fistulas are abnormal vascular shunts, allowing blood to flow either directly or indirectly from the carotid artery into the cavernous sinus. Carotid-cavernous fistulas have been classified according to the hemodynamic properties, etiology, or anatomy of the fistula. Hemodynamic classification separates CCFs into high-flow and low-flow fistulas. Etiological classification distinguishes spontaneous lesions from those occurring due to trauma. Anatomical classification defines direct CCFs as those arising directly from the carotid artery, while indirect CCFs are those originating from carotid artery branch vessels. ${ }^{1}$

1. Dr. Mst. Shamima Sultana, Neurosurgeon, Assistant Registrar, Department of Neurosurgery, Rangpur Medical College Hospital, Rangpur, Bangladesh.

2. Dr. Md. Shafiqul Islam, Associate Professor, Department of Neurosurgery, Dhaka Medical College, Dhaka, Bangladesh.

3. Dr. Md. Sumon Rana, Medical Officer, Department of Neurosurgery, Dhaka Medical College Hospital Dhaka, Bangladesh.

4. Dr. Kanij Fatema Ishrat Zahan Rifat, Assistant Professor, Department of Neurosurgery, Dhaka Medical College, Dhaka, Bangladesh.

5. Dr. Md Abul Kalam Azad, Assistant Professor, Department of Medicine, Rangpur Medical College, Rangpur Bangladesh.

6. Dr. Md Motasimul Hasan, RS Neurosurgery, Dhaka Medical College Hospital, Dhaka, Bangladesh.

7. Dr. Ayub Ansari, Associate Professor, Department of Neurosurgery, Bangabandhu Sheikh Mujib Medical University, Bangladesh

8. Dr Asit Chandra Sarker, Professor and Head, Department of Neurosurgery, Dhaka Medical College, Dhaka, Bangladesh.

9. Dr ANM llias, Assistant Professor, Department of Neurosurgery, Comilla Medical College, Bangladesh.

10. Dr. Md. Rezaul Alam, Associate Professor Neurosurgery. Rajshai Medical College.

Address of Correspondence: Dr. Mst. Shamima Sultana, Neurosurgeon, Assistant Registrar, Department of Neurosurgery, Rangpur Medical College Hospital, Rangpur, Bangladesh, Phone 01972554707, E-mail: shamimaneuro@gmail.com. 

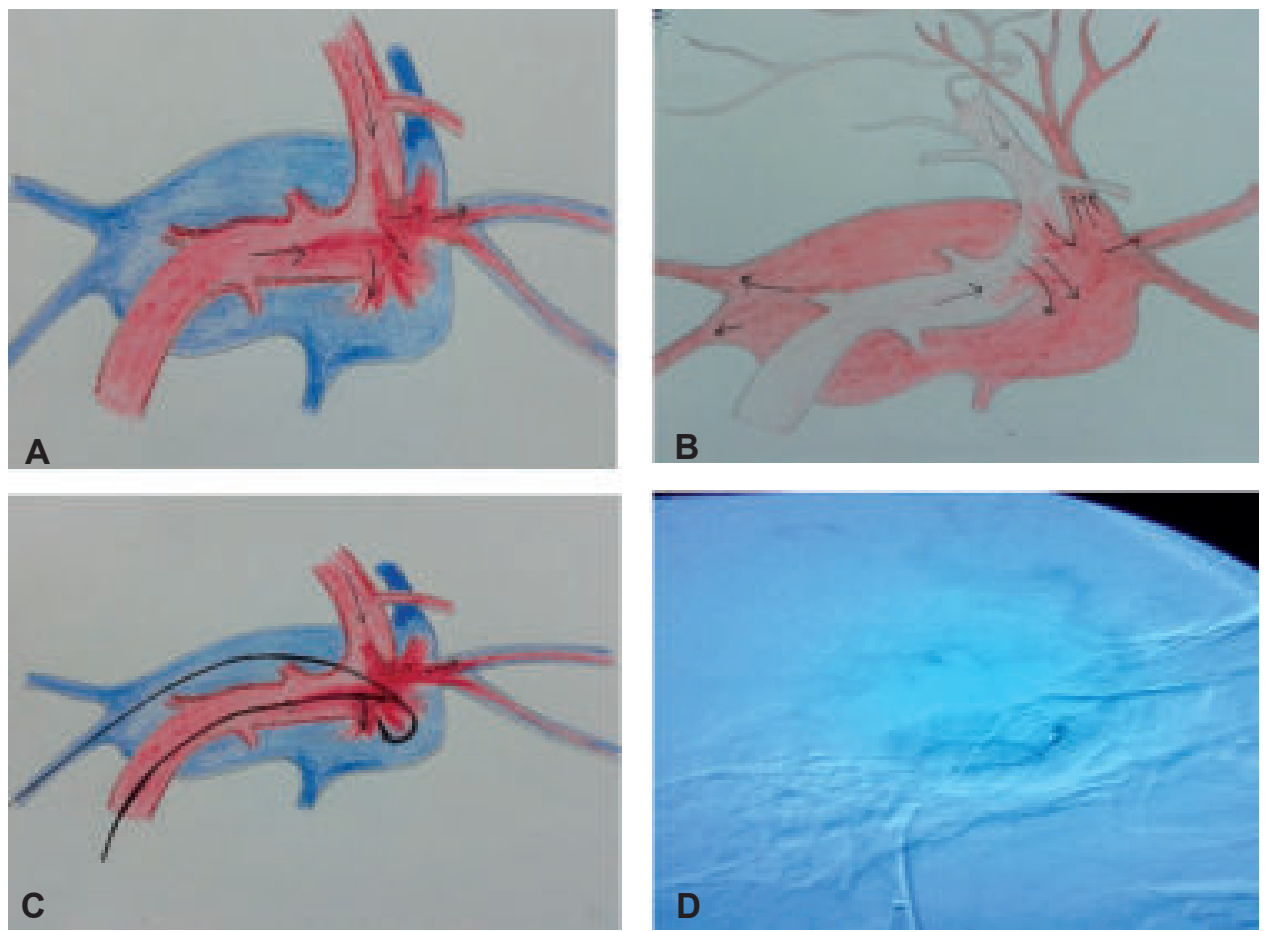

Fig.-1: Diagrammatic image showing (A) Shunt between ICA and cavernous sinus (B) Arterial steal (C) (D) Placement of arterial and venous catheter in simple coiling via transvenous route.

Based on the nomenclature of Peeters and Kröger, ${ }^{2}$ Barrow et al. ${ }^{3}$ defined 4 types (Types A-D) of CCFs. Type CCFs are direct, high-flow lesions connecting the ICA directly to the cavernous sinus. Type B, C, and D CCFs are all indirect, low-flow lesions that arise from meningeal branches of either the ICA or ECA. Type $B$ CCFs arise from meningeal branches of the ICA, Type $C$ CCFs arise from meningeal branches of the ECA, and Type D CCFs arise from meningeal branches of the ICA and ECA. ${ }^{3}$

Type A CCFs (Direct) often result from a single tear in the carotid artery wall, caused either by trauma or aneurysm rupture. These are by far the most common type of CCFs, accounting for approximately $75 \%-$ $80 \%$ of CCFs overall. 3,4

CCFs drain toward anterior via ophthalmic veins, inferior via pterygoid plexus and inferior petrosal sinus (IPS), contralateral via intercavernous connections, posterior via deep venous system, superior petrosal sinus (SPS), and cerebellar veins, and superior via superficial middle cerebral vein (SMCV). Mostly patients present with orbital symptoms secondary to anterior drainage but clinical presentation may change according to venous drainage pattern. Less commonly, headache, altered mental status, and other neurological deficits such as ischemia or infarction secondary to venous hypertension or steal phenomena may occur. ${ }^{7-12}$

The most common presenting signs and symptoms include proptosis in 72\%-98\%, 5,6,13,14 chemosis in $55 \%-100 \%, 6,13,14$ orbital bruits in $71 \%-80 \%, 5,6,14$ and headache in $25 \%-84 \%$ of patients. ${ }^{6,13}$ Additionally, the majority of patients complain of visual disturbances, including diplopia reported in $88 \%$ of patients, blurry vision, and orbital pain. 4,5,6,13,14,15 These visual complaints may be due to retinal ischemia and may indicate the need for urgent intervention. Ophthalmoplegia has been reported in $23 \%-63 \%$ of patients, ${ }^{6,14}$ while other cranial nerve deficits have been reported in $17 \%-44 \%$ of patients.

${ }^{13}$ Less common presentations include intracerebral or subarachnoid hemorrhage in $5 \%$ of patients. ${ }^{13}, 16$

Urgent treatment is usually needed for direct and high flow fistulas in which endovascular embolization is mostly applied. Indirect, slow flow CCFs usually close spontaneously without treatment. ${ }^{3,7,10,12}$

\section{Patients and Methods:}

We report the successful occlusion of nine CCF (eight cases Barrow type $A$ and one case of type $D$ ) using coils, balloon and liquid (NBCA) embolic material 
during a period of three years (2015 to 2017). There were eight males and one female with a mean average age of 36 Years. Using a Siemens Monoplane Artis Zee; all the procedures were done under general anesthesia except in one patient done under local anesthesia.

A bolus injection of heparin $(5,000 \mathrm{IU})$ was administered before placement of the guide catheter into the internal carotid, and an additional 1,000-IU bolus of heparin was administered every hour. All patients were tested for permanent internal carotid artery sacrifice angiographically by venous phase timing during balloon test occlusion (BOT). ${ }^{17}$

All patients with direct CCF had history of trauma except one. Two patients had associated EDH for which they were operated. In all patients with direct CCF there was a gap between trauma and appearance of symptoms. All patients present with pulsatile proptoses, chemosis and orbital pain. CTA done showed the dilated tortuous superior ophthalmic vein (SOV) consistent with the diagnosis of cavernous sinus fistula. In one case venous drainage was posterior through superior petrosal sinus.

The arterial route was used in the treatment of seven patients (patient 2-7 and 9) and in another two patients (patient 1 and 8 ) it was done by trans-venous route. By placing a $6 \mathrm{~F}$ sheath in the femoral artery through which a $6 \mathrm{~F}$ guiding catheter is advanced till the origin of the internal carotid artery (ICA). In dural
CCF cases (patient 2) the arterial approach was used as a route for treatment and to introduce glue.

\section{Results:}

In patients with direct CCF Digital Subtraction Angiography (DSA) revealed direct fistula (Barrow A) between the cavernous carotid (ICA) and the cavernous sinus with variable degrees of failure to opacify the distal supraclinoid and intracranial carotid due to steel effect of the fistula and arterializations of cortical veins. In patients with Indirect CCF, DSA showed that the fistula is supplied from both ICA and ECA (Barrow D).

PatientsProptosis immediate post op Mortality Improvement of vision Obliteration of Fistula Residual fistula.

The traumatic CCF was crossed to the cavernous sinus using a microcatheter. In case 1 (Fig. 2) test occlusion was negative and the ICA had to be spared. In balloon assisted coiling a 4X15mm balloon (Hyper Glide -occlusion balloon system- EV3, USA) was placed in the cavernous carotid to be intermittently inflated during embolization to prevent the reflux of the embolizing material in the ICA. The sinus was packed with electrically detachable platinum coils (GDC-10 \& GDC-18 Axium-Microtherapeutics- EV3) to occlude the sinus (cases 5, 6, 9). Adding liquid embolic material to complete sinus occlusion was done by using N-Butyl Cyanoacrylate (NBCA) in case 2 and 7.

Table-I

Patients data, type of CCF, treatment option used, occlusion test result and post-procedure outcome.

\begin{tabular}{|c|c|c|c|c|c|c|c|c|}
\hline Patients & Sex & Age(yrs) & Type of CCF & Treatment option & Route & Procedure outcome & Repeat Rx & Occlusion test \\
\hline Pat.(1) & $M$ & 20 & Barrow $\mathrm{A}$, right & Coil & Transvenous & CCF closure & - & - \\
\hline Pat.(2) & M & 38 & Barrow D, left & Glue & Transarterial & CCF closure & - & + \\
\hline Pat.(3) & M & 35 & Barrow $A$, right & Coil & Transarterial & ICA occlusion & - & + \\
\hline Pat.(4) & M & 13 & Barrow A, left & Coil & Transarterial & CCF closure & - & + \\
\hline Pat.(5) & M & 33 & Barrow A, left & Coil & Transarterial & Residual fistula & $\begin{array}{c}\text { Balloon } \\
\text { assisted coiling }\end{array}$ & + \\
\hline Pat.(6) & M & 31 & Barrow A, left & $\begin{array}{l}\text { Balloon } \\
\text { assisted coiling }\end{array}$ & Transarterial & CCF closure & - & - \\
\hline Pat.(7) & M & 12 & Barrow $A$, right & Glue & Transarterial & ICA occlusion & Died & + \\
\hline Pat.(8) & $\mathrm{F}$ & 32 & Barrow A, right & Coil & Transvenous & CCF closure & - & + \\
\hline Pat.(9) & M & 40 & Barrow A, left & $\begin{array}{l}\text { Balloon } \\
\text { assisted coiling }\end{array}$ & Transarterial & CCF closure & - & - \\
\hline
\end{tabular}



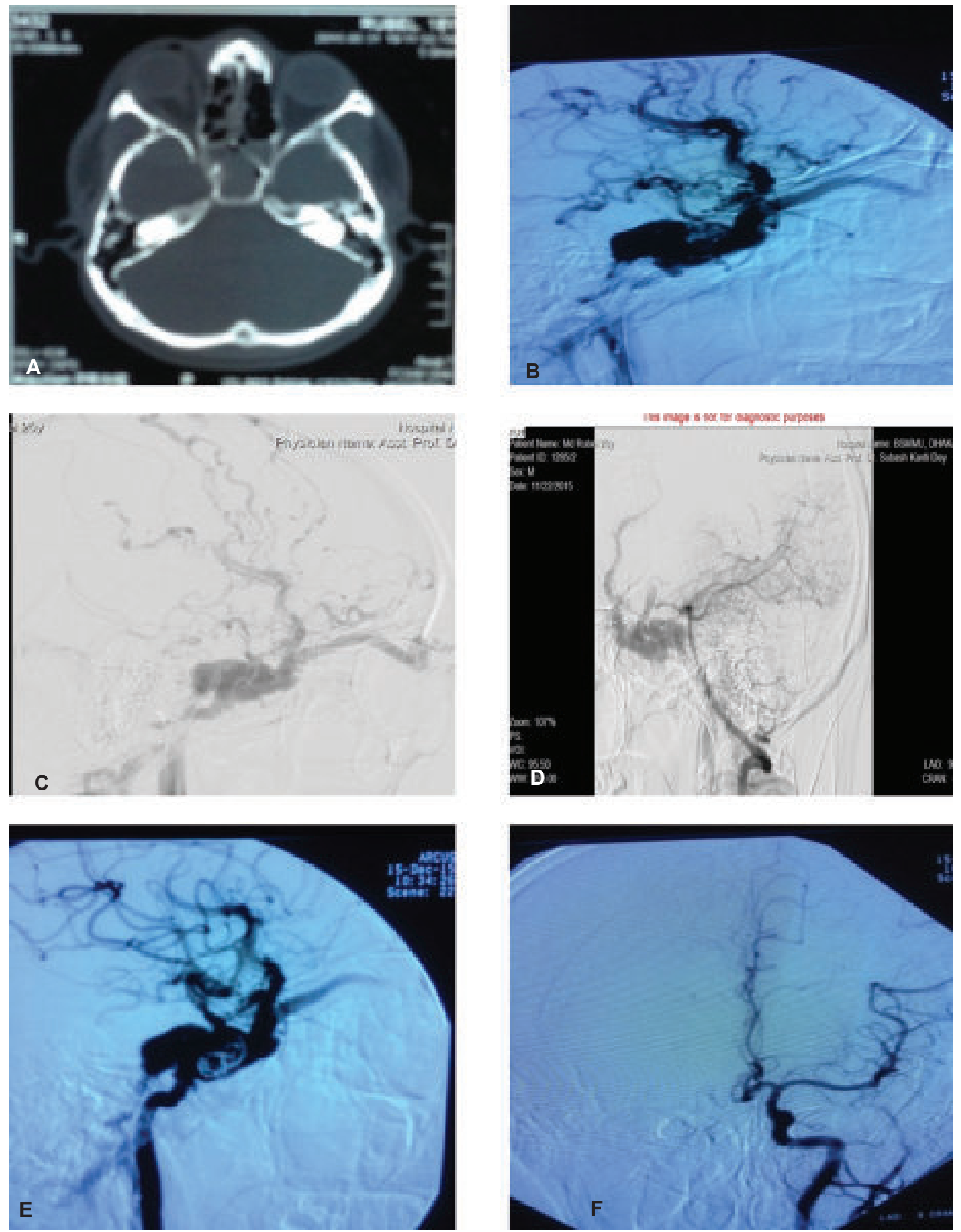

Fig. 2: Transvenous Simple Coiling A) Showing fracture in right sphenoid bone, B) Arterializations of cortical veins and arterial steal, C) Shunt between ICA and cavernous sinus, D) Visualization of CCF through P-com, E) Right ICA post embolization with simple coiling by transvenous route, F) Complete closure of the fistula and restoration of intracranial flow. 

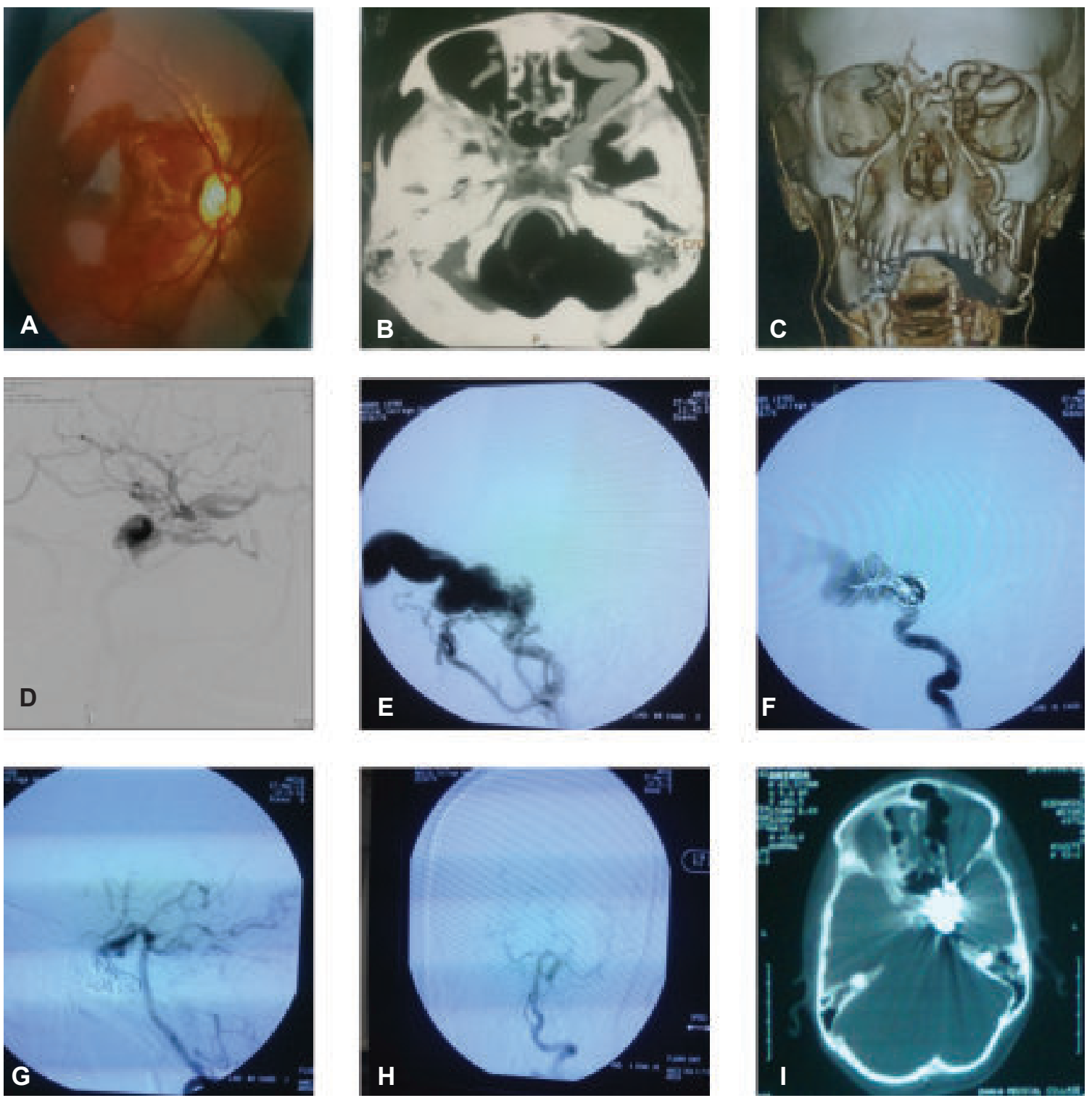

Fig.-3: Transarterial simple coiling A) Fundus photography revealed Papilloedema (B) (C) CT-angiogram reveals dilated superior ophthalmic vein $(D)(E)$ Visualization of CCF $(F)$ Transarterial deployment of simple coil $(G)(H)$ Non Visualization of CCF through VA and ICA injection (I)After deployment of coil CT scan of head.

Table-II

Showing Post operative complications and Outcome

\begin{tabular}{llllll}
\hline Pat (1) & No & No & Yes & Yes & No \\
\hline Pat (2) & No & No & Yes & Yes & No \\
Pat (3) & Yes & No & Yes & Yes & No \\
Pat (4) & Yes & No & Yes & Yes & No \\
Pat(5) & No & No & Yes & No & Yes \\
Pat (6) & No & No & Yes & Yes & No \\
Pat (7) & No & Died & No & Yes & No \\
Pat (8) & No & No & Yes & Yes & No \\
Pat (9) & No & No & Yes & Yes & No \\
\hline
\end{tabular}



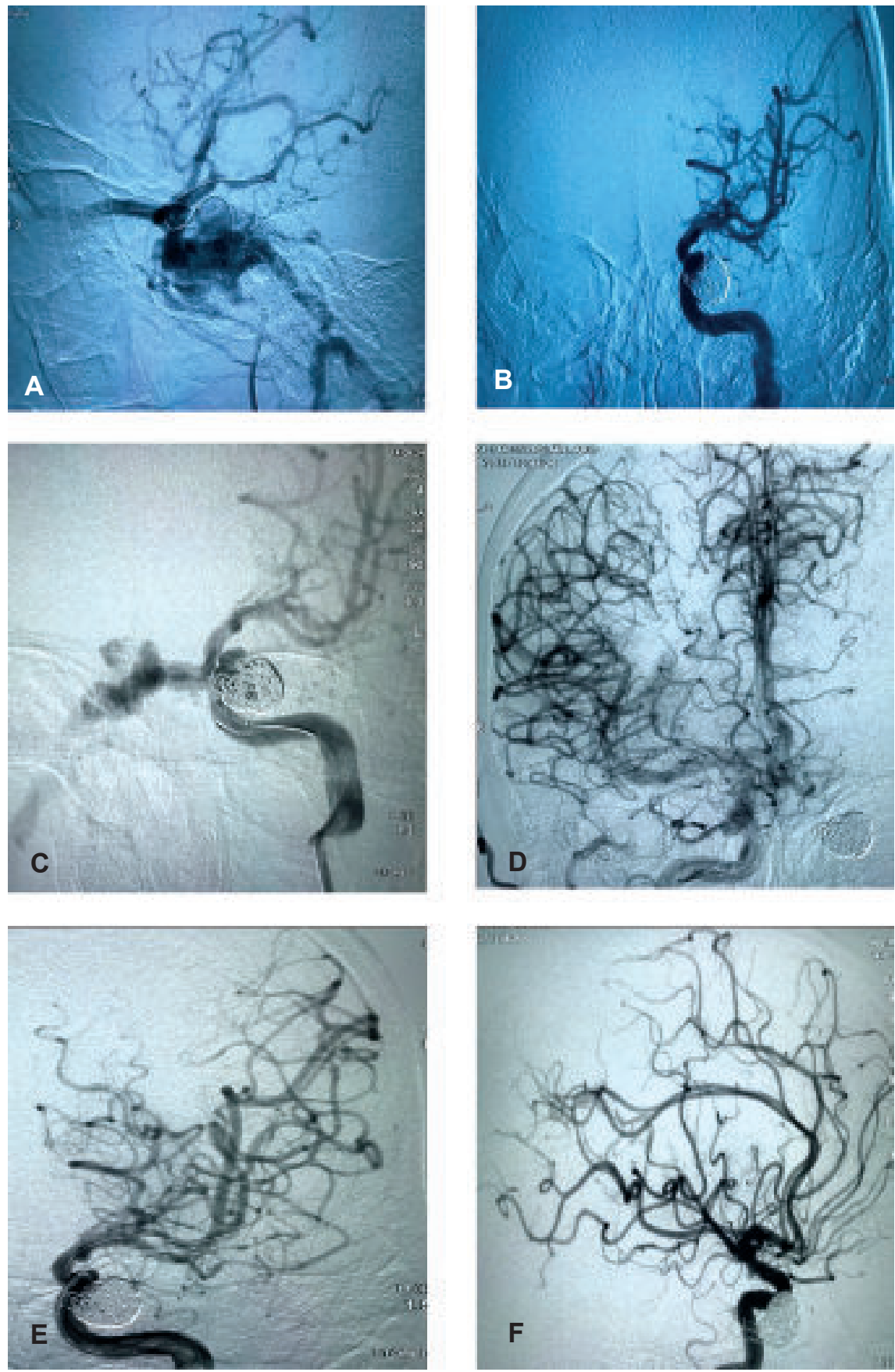

Fig.-4: Balloon assisted coiling (Transarterial) with position of placement of Balloon across the CCF

\section{Discussion:}

Type A fistulas are high flow fistulas that show spontaneous resolution in only $0.05 \% 18,19$ hence, they usually require therapeutic intervention. The decision to treat a dural CCF requires recognition of the patient and physician that the signs and symptoms merit the risks of the intervention. The choice of treatment modalities depends on the anatomy of Fistula determined by DSA, cross flow, availability of materials and cost effectiveness. Higher risks fistulas associated with neurological deficits, intradural hemorrhage, venous thrombosis, or altered mental status deserve the most aggressive measures to eradicate the fistula. Low-risk lesions with mild symptomatology may not require active intervention and can be managed expectantly. Patients with lowrisk lesions can be given reassurance, educated regarding potential changes in 
Symptoms, and allowed time for potential spontaneous closure of the fistula 20,21

The goal of treatment in direct CCFs is to occlude the site of communication between the ICA and the cavernous sinus while preserving the patency of the ICA. This goal can be accomplished through either transarterial obliteration of the fistula with a detachable balloon ${ }^{22-27}$ or trans-arterial or transvenous obliteration of the ipsilateral cavernous sinus with coils or other embolic materials ${ }^{17,24-28}$ or deployment of a covered stent across the fistula. ${ }^{29}$

In our study Transvenous simple coiling (Fig-2) done in two (Pat 1 and Pat 8) patients. Keeping arterial catheter (through right femoral artery) in situ venous catheter (through femoral vein) proceeds via inferior petrosal sinus to cavernous sinus then to the fistulous point in ICA. The detachable coils are packed in the sinus preferably near the fistulous point. There was complete obliteration of fistula after packing coils. Post-operatively some proptosis remains but chemosis and vision was improved dramatically. In three months follow up there was no residual fistula angiographically and no reappearance of symptoms.

In our study three cases (Pat- 3, 4, 5) with direct CCF were treated by simple coiling through Transarterial route. Detachable coils placement in the site of fistula in ICA proven an excellent therapeutic option for traumatic fistula occlusion under circumstances when detachable balloons cannot be used or not available. Detachable coils also have their limitations of parent artery occlusion or thromboembolism by herniation or jumping ${ }^{30}$ of coils into the parent vessel. In Case 3 patient had very good cross flow and unable to bear the cost of coils and balloons, we decided to occlude ICA in the affected side (right) under local anaesthesia with occlusion coils, which is very cheap. Vision was improved but some proptosis remains in patient in follow up. In Case 4 successful obliteration of direct CCF achieved through transarterial route by GDC coil. Vision was improved but some proptosis remains in follow up (Fig-3). In case 5 there was direct Barrow type A fistula that was occlude by transarterial simple coil placement. During procedure there was some coil migration in parent artery. Post-operatively patient improves. His proptosis reduced and visual impairment improved. But after two months patient again develop proptosis and chemosis. DSA revealed some potion of fistula remains then we again do transarterial balloon assisted coiling with complete obliteration of fistula. In three months follow up patient improved both clinically an angiographically.

We treated 3 cases by Transarterial balloon assisted sinus coiling technique. All cases were done under general anesthesia. Percutaneous access was obtained via right Femoral artery and 6F-guiding catheter was introduced in distal ICA. Balloon was taken to cavernous ICA and kept in appropriate place. A microcatheter was inserted into the cavernous sinus over a 0.014-inch microwire through the fistulous point; the microcatheter was placed distal from the fistula point, and a "U-turn" maneuver was performed. Through the same carotid access, a compliant balloon was advanced to cross the point of the fistula and cover the whole carotid tear. Large coils were inserted using the microcatheter in the cavernous sinus. Coils filled the adjacent cavernous sinus, respecting the balloon. Immediate complete angiographic resolution was achieved.

A study done by Andrade et al ${ }^{31}$ achieved excellent clinical and angiographic results in all of them. No complications or any adverse effects were observed. Immediate complete angiographic resolution was achieved, and an early control angiography (mean= 2.6 months) showed complete stability without any recanalization.

In our two patients we used Glue (NBCA). In case 2 there was Barrow type D CCF, we used NBCA through transarterial route to occlude the fistulous point. We achieved successful angiographic occlusion of fistula

$\mathrm{N}$ - Butyle-Cyanoacryate (NBCA) was the commonly used liquid embolic material to occlude the CCF direct or dural. ${ }^{26}$ However, it provides limited time of injection, and may polymerize and glue the microcatheter inside the sinus. In contrast to NBCA Ethylene-vinyl alcohol copolymer (Onyx) is a nonadhesive liquid that allows a longer injection time and rates and can be used safely and showed excellent penetration in the different compartments of the cavernous sinus allowing longer duration and controlled injection. ${ }^{15-20}$

In our study we do not used Onyx in any case. In indirect (dural) CCF the goal of treatment is to interrupt the fistulous communications and decrease the pressure in the cavernous sinus. This goal can be accomplished by occluding the arterial branches 
supplying the fistula (transarterial embolization) or, more effectively, by occluding the cavernous sinus that harbors the fistulous communication (transvenous embolization). ${ }^{32}$

In our case 7 a 12yrs old poor boy there was Direct CCF. Patient can't afford coil or balloon. As cross flow was better, we first proximally occlude ICA by occlusion coil (cheap). There was cross flow through Pcom and opposite carotid. Then we go through vertebral artery to Pcom to ICA distal to fistula and injected glue to occlude the carotid distal to fistula with an intention to trap the fistula. But unfortunately glue flies away here and there due to still high flow through fistula. Postoperatively patient developed huge $\mathrm{SAH}$ and the patient died possibly due venous hypertension.

\section{Conclusion}

Trans-venous approach to CCF is the treatment of choice. Transarterial balloon assisted sinus coiling technique to occlude the CCF just what we do for aneurysm is a very good alternative. It does not have any issue of access difficulty to the sinus. Transarterial detachable balloon occlusion of the CCF is easier and cheaper also, which was popular before is coming in the field again with newer balloons. This seems to be very useful and cost effective in our perspective.

\section{References:}

1. Jason AE, Hannah G, Sander CJ and Philip MM. Carotidcavernous fistulas. Neurosurg Focus 2012; 32 (5): E9.

2. Peeters FL, Kröger R. Dural and direct cavernous sinus fistulas. AJR Am J Roentgenol 1979; 132: 599-606.

3. Barrow DL, Spector RH, Braun IF, Landman JA, Tindall SC and Tindall GT. Classification and treatment of spontaneous carotid-cavernous sinus fistulas. J Neurosurg 1985; 62: 248256.

4. Debrun G M, Viñuela F, Fox A J, Davis K R and Ahn H S. Indications for treatment and classification of 132 carotidcavernous fistulas. Neurosurgery 1988; 22: 285-289.

5. de Keizer R. Carotid-cavernous and orbital arteriovenous fistulas: ocular features, diagnostic and hemodynamic considerations in relation to visual impairment and morbidity. Orbit 2003; 22:121-142.

6. Lewis Al, Tomsick TA, Tew JM. Management of 100 consecutive direct carotid cavernous fistulas: results of treatment with detachable balloons. Neurosurgery 1995; 36 : 239-245.

7. Fattahi TT, Brandt MT, Jenkins WS, and Steinberg B. Traumatic carotid-cavernous fistula: pathophysiology and treatment. The Journal of Craniofacial Surgery 2003; 14(2): 240-246.
8. Wang HX, Bai RL, Huang CG, Lu YC and. Zhang GJ. Hemiparesis in carotid cavernous fistulas (CCFs): a case report and review of the literature. Chinese Journal of Traumatology 2004; 7(5): 317-320.

9. Murata H, Kubota T, Murai M, Kanno H, Fujii S and Yamamoto I. Brainstem congestion caused by direct carotid cavernous fistula—case report. Neurologia Medico-Chirurgica 2003; 43(5): 255-258.

10. Th'eaudin M, Saint-Maurice JP and Chapot R. Diagnosis and treatment of dural carotid-cavernous fistulas: a consecutive series of 27 patients. Journal of Neurology, Neurosurgery and Psychiatry 2007: 78(2): 174-179.

11. Suh DC, Lee JH and Kimet SJ. New concept in cavernous sinus dural arteriovenous fistula: correlation with presenting symptom and venous drainage patterns. Stroke 2005; 36(6): 1134-1139.

12. Kirsch M, Henke $H$ and Liebig T. Endovascular management of dural carotid-cavernous sinus fistulas in 141 patients. Neuroradiology 2006; 48(7): 486-490.

13. Gupta AK, Purkayastha S, Krishnamoorthy T, Bodhey NK, Kapilamoorthy TR and Kesavadas C. Endovascular treatment of direct carotid cavernous fistulae: a pictorial review. Neuroradiology 2006; 48: 831-839.

14. Wang W, Li YD, Li MH, Tan HQ, Gu BX and Wang J. Endovascular treatment of post-traumatic direct carotidcavernous fistulas: A single-center experience. J Clin Neurosci 2011; 18: 24-28.

15. Kupersmith MJ, Berenstein A, Flamm E and Ransohoff J. Neuroophthalmologic abnormalities and intravascular therapy of traumatic carotid cavernous fistulas. Ophthalmology 1986; 93: 906-912.

16. Huai RC, Yi CL, Ru LB, Chen GH, Guo HH and Luo L. Traumatic carotid cavernous fistula concomitant with pseudoaneurysm in the sphenoid sinus. Interv Neuroradiol 2008; 14:59-68.

17. Abud DG, Spelle L, Piotin M, Mounayer C, Vanzin JR and Moret $\mathrm{J}$. Venous phase timing during balloon test occlusion as a criterion for permanent internal carotid artery sacrifice. AJNR Am J Neuroradiol 2005; 26(10):2602-9.

18. Henderson JW, Schneider RC. The ocular findings in carotidcavernous fistula in a series of seventeen (17) cases. Am J Ophthalmol 1959; 48: 585-597.

19. Kawaguchi S, Sakaki T, Morimoto T, Hoshida T, Nakase H. Surgery for dural arteriovenous fistula in superior sagittal sinus and transverse sinus. J Clin Neurosci 2000; 7:47-9.

20. Halbach VV, Hieshima GB, Higashida RT, Reicher M. Carotid cavernous fistulae: indications for urgent treatment. AJRAm J Roentgenol 1987; 149:587-93.

21. Magidson MA, Weinberg PE. Spontaneous closure of a dural arteriovenous malformation. Surg Neuro 1976; 16:107-10.

22. Debrun G, Lacour P, Caron JP, Hurth M, Comoy J, Keravel Y. Detachable balloon and calibrated-leak balloon techniques in the treatment of cerebral vascular lesions. J Neurosurg 1978; 49:635-49. 
23. Fang C, Li MH, Tan HQ, Zhang PL, Zhou B. Endovascular treatment of pseudo-aneurysm occurring after embolization of traumatic carotid cavernous fistula with detachable balloons. Chin Med J (Engl) 2008; 121:1487-91.

24. Suzuki S, Lee DW, Jahan R, Duckwiler GR, Vinuela F. Transvenous treatment of spontaneous dural carotidcavernous fistulas using a combination of detachable coils and Onyx. AJNR Am J Neuroradiol 2006; 27:1346-9.

25. Andres RH, Remonda L, Do DD, Spreng A, Reinert M, Schroth G. Diagnosis and treatment of carotid cavernous fistulas. Rofo 2008; 180:604-13.

26. Wakhloo AK, Perlow A, Linfante I, Sandhu JS, Cameron J, Troffkin N, et al. Transvenous n-butyl-cyanoacrylate infusion for complex dural carotid cavernous fistulas: technical considerations and clinical outcome. AJNR Am J Neuroradiol 2005; 26:1888-97.

27. Serbinenko FA. Balloon catheterization and occlusion of major cerebral vessels. J Neurosurg 1974; 41:125-45.
28. Mounayer C, Hammami N, Piotin M, Spelle L, Benndorf G, Kessler I, et al. Nidal embolization of brain arteriovenous malformations using Onyx in 94 patients. AJNR Am J Neuroradiol 2007; 28:518-23.

29. Archondakis E, Pero G, Valvassori L, Boccardi E, Scialfa G. Angiographic follow-up of traumatic carotid cavernous fistulas treated with endovascular stent graft placement. AJNR Am J Neuroradiol 2007; 28:342-7.

30. Choi BJ, Lee TH, Kim CW, Choi CH. Endovascular graftstent placement for treatment of traumatic carotid cavernous fistulas. J Korea Neurosurg Soc. 2009; 46:572-6.

31. Andrade G, Souza1 ML, Marques R, Silva JL, Abath C, Filho H. Endovascular Treatment of Traumatic Carotid Cavernous Fistula with Balloon-Assisted Sinus Coiling A Technical Description and Initial Results. Interventional Neuroradiology 2013; 19: 445-454.

32. Gemmete JJ, Ansari SA, Gandhi D. Endovascular treatment of carotid cavernous fistulas. Neuroimaging Clin NAm.2009; 19:241-55. 